et al. High-sensitivity versus conventional troponin in the emergency department for the diagnosis of acute myocardial infarction. Crit Care. 2011;15(3):R147. doi:10.1186/cc10270

8. Collet J-P, Thiele H, Barbato E, et al. 2020 ESC
Guidelines for the management of acute coronary syndromes in patients presenting without persistent ST-segment elevation. European Heart Journal. 2021;42(14):1289-1367. doi:10.1093/ eurheartj/ehaa575

\title{
PHÂN TÍCH GEN SLC25A20 VÀ CPT2 TRONG CHẨN ĐOÁN KHIẾM KHUYẾT BETA OXI HOÁ CỦA AXÍT BÉO Ở TI THỂ
}

\author{
Phạm Thúy Ngọc ${ }^{1}$, Bùi Thị Bảo², Tạ Văn Thạo³, \\ Vũ Chí Dũng ${ }^{4}$, Trần Thị Chi Mai ${ }^{3,4}$
}

\section{TÓM TĂT}

Bệnh lí thiếu hụt Carnitine/acylcarnitine transferase (CACT) và bệnh lí thiếu hụt Carnitine palmitoyltransferase II (CPT II) thuộc nhóm bệnh oxi hóa axit béo trong ti thê. CACT và CPT II là các bệnh lí rối loạn chuyển hóa bẩm sinh (RLCHBS) di truyền hiếm gặp - biến thể di truyền lặn nhiễm sắc thể thường do gen SLC25A20 (gen CACT) và gen CPT2 quy định. Đây là các bệnh lí nguy hiểm để lại các di chứng nặng nề và có thể tử vong. Tuy nhiên, CACT và CPT II có các đặc điểm lâm sàng và cận lâm sàng khá giống với các bệnh lí RLCH oxi hóa axit béo khác và không thể phân biệt về đặc điểm cận lâm sàng và lâm sàng giữa hai bệnh lí này do vầy cân có các phương pháp phù hợp, nhanh chóng để xác định biến thể trên gen SLC25A20 và CPT2 nhằm chẩn đoán và điều trị bệnh. Mục tiêu: Xác định 16 biến thể gen SLC25A20 và 35 biến thể gen CPT2; mô tả kiểu hình và kiểu gen của bệnh nhân mắc biến thể gen SLC25A20/CPT2. Phương pháp: Nghiên cứu ca bệnh gồm mô tả triệu chứng lâm sàng, xét nghiệm sinh hóa và phân tích gen dựa trên phương pháp xây dựng được. Kết quả: Bé gái 10 ngày tuổi, xuất hiện tím tái, ngừng tim, ngưng thở và tử vong. Kết quả xét nghiệm sinh hóa và xét nghiệm amio acid cho thấy hạ glucose máu, nhiễm toan chuyển hóa, tăng amoniac máu; tăng C4, C10, C12, C14, C14OH, C16, C16:1, $\mathrm{C} 16: 10 H$, $\mathrm{C} 18$ và $\mathrm{C} 18: 1$. Bệnh nhân được xác định có biến thể rs541208710, c.199-10T>G dạng đồng hợp tử trên gen SLC25A20 và 2 biến thể lành tính/ có thể lành tính với bệnh CPT II là rs2229291 (F352C) (c.1055T>G (p.Phe352Cys)) và rs1799821 (V368I) (c.1102G >A (p.Val368Ile)) do vây chẩn đoán bênh di truyền mắc phải là bệnh CACT. Kết luận: Xác định 16 biến thể gen SLC25A20 và 35 biến thể gen CPT2 cho phép chẩn đoán xác định bệnh lí RLCHBS di truyền CACT và CPT II.

\footnotetext{
${ }^{1}$ Bệnh viện Phổi Trung Uơng

${ }^{2}$ Công ty cổ phần Chemedic Việt Nam

${ }^{3}$ Đại họ Y Hà Nọi

${ }^{4}$ Bệnh viện Nhi Trung Uơng

Chiu trách nhiệm chính: Ta Văn Thạo

Email: tavanthao@hmu.edu.vn

Ngày nhận bài: 9.9.2021

Ngày phản biên khoa họ: 29.10.2021

Ngày duyệt bài: 9.11.2021
}

Tư khóa: Rối loạn chuyển hóa bẩm sinh (RLCHBS), thiếu hụt Carnitine/acylcarnitine (CACT), thiếu hụt Carnitine palmitoyltransferase II (CPT II), gen SLC25A20, gen CPT2.

\section{SUMMARY}

ANALYSIS OF SLC25A20 AND CPT2 GENES IN THE DIAGNOSIS OF MITOCHONDRIAL FATTY ACID BETA-OXIDATION DEFECT

Carnitine-acylcarnitine translocase deficiency (CACT) and Carnitine palmitoyltransferase II deficiency (CPT II) are disorders of mitochondrial fatty acid $\beta$-oxidation (FAO), type of metabolism inborn errors. These conditions are inherited in an autosomal recessive pattern, the gene associated with this disorder respectively SLC25A20 (CACT gene) and CPT2 gene. CACT and CPT II are dangerously disordered and may have severe consequences and even death. But these disorders had similar and nonspecific clinical symptoms also testing with another FAO disorder and other metabolism inborn errors or congenital defect, specifically, cannot distinguish and diagnostic between CACT and CPT II disorder. Therefore, this is necessary for a suitable method and quicky time for diagnostic mutation in SLC25A20 and CPT II gene to diagnostic and treat diseases. Objectives: to identify 16 mutations in the SLC25A20 gene and 35 mutations in the CPT2 gene to describe the phenotype and genotype of the patient who had SLC25A20/CPT2 mutation. Methods: case study including clinical symptom descriptions and identifying SLC25A20/CPT2 mutation. Results: the newborn girl-patient 10 days old with clinical symptoms include cyanosis, cardiac arrest, apnea, and death. The blood testing reveals that decrease glucose, metabolism acidosis, hyperammonemia, increase C4, C10, C12, C14, C14OH, C16, C16:1, $\mathrm{C} 16: 1 \mathrm{OH}, \mathrm{C} 18$ and $\mathrm{C} 18: 1$. The genetic test showed that the patient had one pathology homozygous mutation rs541208710, c.199-10T>G in SLC25A20 gene and two other mutation - benign/likely benign with CPT II deficiency in CPT2 gene are rs2229291 (F352C) (c.1055T > G (p.Phe352Cys)) and rs1799821 (V368I) (c.1102G $>$ A (p.Val368Ile)). The diagnosis is CACT deficiency. Conclusion: Identifying 16 mutations in the SLC25A20 gene and 35 mutations in the CPT2 genes can help to diagnostic CACT/CPT II deficiency. 
Keyword: Metabolism inborn errors, Carnitineacylcarnitine translocase deficiency (CACT), Carnitine palmitoyltransferase II deficiency (CPT II), SLC25A20 gene, CPT2 gene.

\section{I. ĐẠT VẤN ĐỀ}

Bệnh lí thiếu hụt Carnitine/acylcarnitine transferase (CACT) và bệnh lí thiếu hụt Carnitine palmitoyltransferase II (CPT II) thuộc nhóm bệnh rối loạn chuyển hóa bẩm sinh (RLCHBS) oxi hóa acid béo $\beta$ (FAO) mạch dài (LC) và mạch trung bình trong ti thể xảy ra tại ma trận ti thể. Tuy nhiên, FAO các acid béo mạch trung bình chủ yếu phụ thuộc vào các enzyme chuyển hóa trong ma trận ti thể nhưng FAO LC là quá trình phức tạp hởn, phụ thuộc vào các protein vận chuyển chất qua màng tế bào và ti thể; enzyme chuyển đổi màng ti thể. Các protein và enzyme vận chuyển quyết định con đường FAO bao gôm protein vận chuyển carnitine từ ngoại bào vào tế bào (OCTN2). Enzyme CPT I ở màng ngoài ti thể gắn carnitine lên LC để tạo thành dạng vận chuyển được - LC-acyl carntinine. LCacylcarnitine được đưa vào ma trận ti thể bằng protein vận chuyển màng trong $\mathbf{C A C T}$, nhưng để có thể oxi hóa, LC cần được tách carnitine nhờ enzyme màng trong CPT2 (Hình 1.1) [1]. Các quá trình oxi hóa tiếp theo của tất cả các dạng axit béo phụ thuộc hoạt động của các enzyme của quá trình oxi hóa. FAO là một trong các nguồn cung cấp năng lượng chính cho các mô trong cơ thể, đặc biệt là mô lây năng lượng chủ yếu từ quá trình oxi hóa acid béo như tim và cơ xương. FAO đóng vai trò cực kì quan trọng khi cơ thể cân nhiều năng lượng và trong suốt khoảng thời gian nồng độ glucose thấp. Các bệnh lí ảnh hưởng đến chức năng của con đường FẢO có thể được xem là các bệnh lí không thể chịu đói hoặc cung cấp năng lượng khi cơ thể cân năng lượng cao - hiện tượng giảm nguôn năng lượng ở nhiều mô trong cơ thể cũng như giảm khả năng sản xuất năng lượng của cơ thể khi nông độ glucose xuống thấp, giảm sản xuất thể ketone ở gan - nguôn acid béo được oxi hóa trực tiếp ở não [8]. Rối loạn chức năng FAO là các bệnh lí hiếm gặp và cực kì nguy hiểm, để lại các di chứng nặng nề và có thể tử vong nhưng các biểu hiện lâm sàng và xét nghiệm không đặc hiệu với các bệnh lí khác và giữa các bệnh lí RLCHBS FAO khác, đặc biệt trong đó có bệnh lí CACT và CPT II có đặc điểm lâm sàng giống nhau như suy hô hấp, co giật, loạn nhịp tim, bệnh cơ tim, bệnh cơ (loạn dưỡng, bại liệt, tiêu cơ vân v.v.), gan to, suy gan, giảm chức năng gan, bệnh thận và bệnh não, tử vong; đặc điểm xét nghiệm gồm giảm glucose máu, giảm ketone máu, có thể tăng amoniac máu, tăng bilirubin, men gan và bất thường rối loạn chuyển hóa MS/MS [7], [8]. Do vậy, cân thực hiện xét nghiệm biến thể gen để chẩn đoán phấn biệt giữa bệnh CACT và CPT II cũng như các RLCHBS khác.

CACT và CPT II là các bệnh lí di truyên lặn nhiễm sắc thể thường do gen SLC25A20 (gen CACT) và CPT2 mã hóa protein CACT và enzyme CPT II quy định tương ứng với protein vận chuyển LC-acyl carnitnine vào ma trận nội bào và enzyme loại bỏ carnitine ra khỏi LC để đi vào quá trình oxi hóa acid béo. Theo công bô trên thư viện gen NCBI, có 16 biến thể gen SLC25A20 và 35 biến thể gen CPT2 gây bệnh CACT/CPT II. Tỉ lệ mắc bệnh CACT là $<1 / 1000000$ và hiện nay có ít hớn 60 ca bệnh được công bố mắc bệnh CACT. Tỉ lệ mắc bệnh CPT II 1 - 9/100000, hiện nay có khoảng hơn 300 ca bệnh được công bố mắc biến thể gen CPT2 trong đó dạng bệnh về cơ chiếm $86 \%$, dạng bệnh nghiêm trọng ở trẻ nhỏ chiếm $8 \%$ và trẻ sơ sinh chiếm 6\% [7], [8].

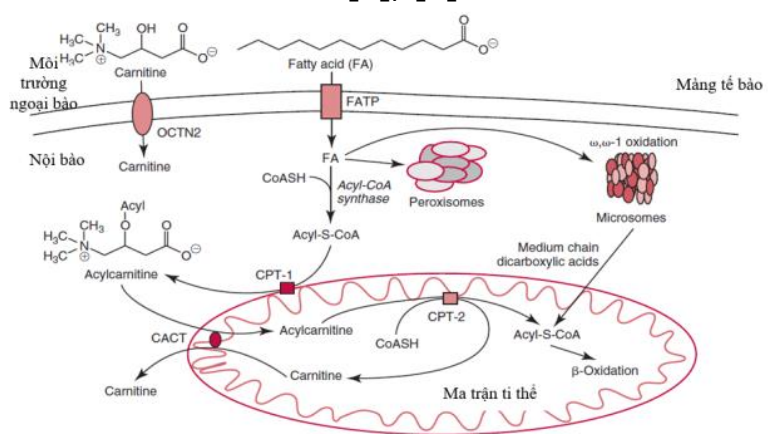

\section{Hình 1.1. Quá trinh vận chuyển và $\beta$-oxi hóa axít béo ở ti thể}

Tuy tỉ lệ mắc bệnh CACT/CPT II là rất hiếm gặp nhưng với các biểu hiện lâm sàng không thể phân biệt và không đặc trưng đặc biệt là ở trẻ sơ sinh/ trẻ nhỏ giữa hai bệnh lí và các bệnh lí RLCHBS cũng như các dị tật bẩm sinh khác do vậy cânn có những biện pháp nhanh chóng và đặc hiệu để chẩn đoán mắc bệnh CACT/CPT II do vậy, nghiên cứu được tiến hành với mục tiêu: Phân tích gen SLC25A20 và CPT2 trong chẩn đoán khiếm khuyết beta oxi hóa của axit béo ở ti thể.

\section{II. ĐỐI TƯỢNG VÀ PHƯƠNG PHÁP NGHIÊN CỨU}

Đối tượng nghiên cứu: Gồm 01 bệnh nhân nhập viện trong tình trạng tím tái, ngừng tuần hoàn.

Phương pháp nghiên cứu: Nghiên cứu ca bệnh bao gồm mô tả đặc điểm lâm sàng, kết quả xét nghiệm (hóa sinh, khí máu, bất thường rối 
loạn chuyển hóa MS/MS) và phân tích biến thể gen. DNA bệnh nhân được tách chiết từ mẫu bệnh phẩm máu khô, phân tích gen sử dụng phương pháp giải trình tự Sanger nhằm xác định 16 biến thể trên gen SLC25A20 và 35 biến thể trên gen CPT2. Các cặp mồi sử dụng để phân tích gen được lấy từ các tài liệu tham khảo [1], [2], [3] và tự thiết kế (Bảng 2.1). Kết quả giải trình tự được phân tích và so sánh với gen SLC25A20 và CPT2 của thư viện gen NCBI (Homo sapiens Updated Annotation Release 109.20191205, GRCh38.p13).

Bảng 2.1. Danh sách các cặp mồi thiêt kề sử dụng trong nghiên cứu

\begin{tabular}{|c|c|c|c|c|}
\hline Gen & Exon & Trình tự mồi & $\begin{array}{l}\text { Kích thước } \\
\text { (bp) }\end{array}$ & $\begin{array}{l}\text { Nhiệt độ ủ } \\
\left(T^{\circ},{ }^{\circ} \mathrm{C}\right)\end{array}$ \\
\hline \multirow{3}{*}{$\begin{array}{l}\text { SLC25 } \\
\text { A20 }\end{array}$} & 3 & $\begin{array}{l}\text { F: CCTTCAGTTTCTCCAGCATAATAGG } \\
\text { R: TATTTAACCCATGTCACGCTACCA }\end{array}$ & 383 & 58.5 \\
\hline & 6 & $\begin{array}{l}\text { F: ACCATACGCTAATGTTAGAAAGCA } \\
\text { R: CACAAGAGGAAAGCAGACATGGA }\end{array}$ & 411 & 58.5 \\
\hline & 8 & $\begin{array}{l}\text { F: GGCATTTGTGCATTTGTCCCA } \\
\text { R: TGCCCACTTCTAATGGCCAGG }\end{array}$ & 515 & 58.5 \\
\hline \multirow{2}{*}{ СРT2 } & 2 & $\begin{array}{l}\text { F: TTGTCAGTCGCTTCTGATTATTGGT } \\
\text { R: ACTACTTGCCAGCCTGTCTTG }\end{array}$ & 274 & 58.5 \\
\hline & 5 & $\begin{array}{l}\text { F: GTTGGTGGTGTGCATAGAGGTAGA } \\
\text { R: ATGATGAGGAAGTGATGGTAGCTTT }\end{array}$ & 514 & 58.5 \\
\hline
\end{tabular}

*F: chiều xuôi (Forward), R: chiều ngược (Reverse)

Đạo đức trong nghiên cứu: Đề tài đã được thông qua Hội đồng đạo đức trong nghiên cứu $Y$ sinh Bệnh viện Nhi Trung Ương mã số IRB $2021-01789$.

\section{KẾT QUẢ NGHIÊN CứU}

3.1. Kết quả phân tích biến thể gen. Thực hiện phân thích 16 biến thể gây bệnh trên gen SLC25A20 và CPT2 cho thây mẫu nghiên cứu mắc 1 biến thể gây bệnh trên gen SLC25A20 biến thể số 04 -rs541208710 ( c.199-10T>G ) ở dạng đồng hợp tử (Hình 3.1 A). Ngoài ra, kết

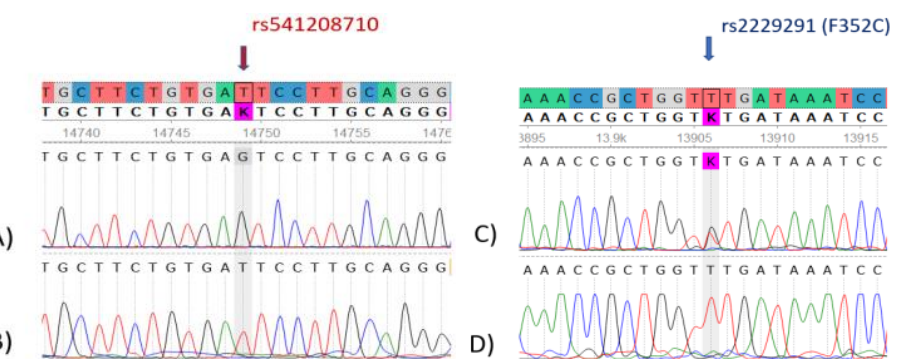

quả phân tích gen còn cho thấy mẫu bệnh phẩm còn mắc 2 biến thể khác trên gen CPT II là rs2229291 (F352C) (c.1055T>G) dạng dị hợp tử và rs1799821 (V368I) (c.1102G>A) dạng đồng hợp tử được liệt kê thuộc dạng biến thể lành tính/ có thể lành tính đối với bệnh CPT II. Tuy nhiên, hai dạng biến thể này có thể gây ảnh hưởng tới chức năng của enzyme CPT II ở các điều kiện nhất định do vậy nhóm nghiên cứu vẫn coi đây là hai biến thể tìm thấy có ý nghĩa (Hình 3.1. C và $E$ )

Hinh 3.1. Hình ảnh biến thể đồng hợp tử rs541208710 (A) và dạng wild type (B) (mẫu chứng); di hợp tử rs2229291 (F352C) (C) và dạng wild type (D) (mẫu chứng); đồng hợp tử rs1799821 (V368I) (E) và dạng wild type $(F)$ (mẫu chứng)

3.2. Đặc điểm lâm sàng và xét nghiệm. Bệnh nhân là bé gái 10 ngày tuổi, nhập viện với các đặc điểm lâm sàng tím tái, ngừng tuần hoàn. Các kết quả sinh hóa máu cho thây glucose tăng, bilirubin trực tiếp tăng, lactat tăng, kết quả xét nghiệm sàng lọc RLCHBS bằng MS/MS có C4, C10, $\mathrm{C} 12$, $\mathrm{C} 14, \mathrm{C} 14 \mathrm{OH}, \mathrm{C} 16$ và $\mathrm{C} 16: 1, \mathrm{C} 18, \mathrm{C} 18: 1$ tăng (Bảng 3.3). Bệnh diễn biến nhanh và chuyển nặng, trên lâm sàng xuất hiện tím tái, ngừng tim, ngưng thở và tử vong. Các kết quả sinh hóa cho thấy hạ glucose máu, nhiễm toan chuyển hóa, tăng amoniac máu.

Bảng 3.3. Kết quả sinh hóa của bệnh nhân trong thời điểm nhập viện

\begin{tabular}{|c|c|c|c|}
\hline Tên xét nghiệm & Kết quả & Khoảng tham chiếu & Đơn vị \\
\hline Định lượng glucose & 5.81 & $2.2-3.3$ & $\mathrm{mmol} / \mathrm{L}$ \\
\hline Định lượng bilirubin trực tiếp & 11.3 & $3.3-7.6$ & $\mathrm{mmol} / \mathrm{L}$ \\
\hline
\end{tabular}




\begin{tabular}{|c|c|c|c|}
\hline Lactat & 7.85 & $1.1-2.3$ & $\mathrm{mmol} / \mathrm{L}$ \\
\hline Sàng lọc RLCHBS & & & \\
\hline Butyrylcarnitine (C4) & 0.92 & $0.05-0.75$ & $\mu \mathrm{mol} / \mathrm{L}$ \\
\hline Decanoylcarnitine (C10) & 0.35 & $0.01-0.26$ & $\mu \mathrm{mol} / \mathrm{L}$ \\
\hline Dodecanoylcarnitine (C12) & 0.52 & $0.03-0.41$ & $\mu \mathrm{mol} / \mathrm{L}$ \\
\hline Tetradecanoylcarnitine (C14) & 1.23 & $0.07-0.5$ & $\mu \mathrm{mol} / \mathrm{L}$ \\
\hline 3-Hydroxy-tetradecanoylcarnitine (C14OH) & 0.06 & $0.0-0.03$ & $\mu \mathrm{mol} / \mathrm{L}$ \\
\hline Hexadecanoylcarnitine (C16) & 11.42 & $0.8-6.0$ & $\mu \mathrm{mol} / \mathrm{L}$ \\
\hline Hexadecenoylcarnitine (C16:1) & 1.19 & $0.02-0.44$ & $\mu \mathrm{mol} / \mathrm{L}$ \\
\hline 3-Hydroxy-hexadecenoylcarnitine (C16:1OH) & 0.17 & $0.0-0.13$ & $\mu \mathrm{mol} / \mathrm{L}$ \\
\hline Octadecanonylcarnitine (C18) & 2.13 & $0.31-1.7$ & $\mu \mathrm{mol} / \mathrm{L}$ \\
\hline Octadecenonylcarnitine (C18:1) & 2.7 & $0.47-2.5$ & $\mu \mathrm{mol} / \mathrm{L}$ \\
\hline
\end{tabular}

\section{BÀN LUÂ̂N}

Hiện nay, có 16 biến thể gen SLC25A20 và 35 biến thể gen CPT2 gây bệnh CACT/CPT II. Kết quả nghiên cứu bằng phương pháp giải trình tự Sanger trên mẫu bênh nhân cho thấy, bênh nhân mắc biến thể đồng hợp tử rs541208710 (Clinvar: NM_000387.6(SLC25A20): c.199$10 T>G$ ). Biến thể đã được tìm thấy ở cả dạng đồng hợp tử và dị hợp tử ở các bênh nhân mắc bệnh CACT, tần suất mang gen là $0.05 \%$ (theo Exome Aggregation Consortium) chủ yếu tìm thấy ở chủng tộc Châu Á. Biến thể SLC25A20 c.199-10T > G tại intron 2, tuy không làm thay đổi trình tự amino acid của protein nhưng biến thể gây bất thường quá trình cắt intron và nối exon - mRNA bị cắt exon 3 hoặc exon 3 và 4 dẫn đến thiếu hụt chức năng protein vận chuyển CACT [3], [4]. Các kết quả lâm sàng và xét nghiệm tại thời điểm tử vong cho thây bao gồm tím tái, ngừng tim, ngưng thở; hạ glucose máu, nhiễm toan chuyển hóa và tăng amoniac máu. Ngoài ra, kết quả xét nghiệm RLCHBS MS/MS cho thây tăng $\mathrm{C} 4, \mathrm{C} 10, \mathrm{C} 12, \mathrm{C} 14, \mathrm{C} 14 \mathrm{OH}, \mathrm{C} 16, \mathrm{C} 16: 1$, $\mathrm{C} 16: 10 \mathrm{H}, \mathrm{C} 18$ và $\mathrm{C} 18: 1$. Kết quả biến thể gen và lâm sàng/ xét nghiệm phù hợp với nhau, khẳng định chẩn đoán mắc bệnh lí RLCHBS thiếu hụt Carnitine/acylcarnitine (CACT).

Ngoài ra, kết quả phân tích gen của bệnh nhân còn tìm thấy biến thể dị hợp rs2229291 (F352C) (c.1055T>G, biến đổi phenylalanine thành cystein ở vị trí amino acid 352) và đồng hợp rs1799821 (V368I) (c.1102G>A, biến đổi valine thành isoleucin ở vị trí amino acid 368). Đây là hai biến thể lành tính/ có thể lành tính đối với bệnh lí CPT II tuy nhiên là biến thể nguy cơ cao đối với bệnh não cấp do nhiễm trùng. F352C và V368I làm giảm tính bền nhiệt - biên thể kém bền nhiệt khi nhiệt độ cơ thể tăng, đặc biệt là trong các trường hợp nhiễm trùng gây sốt. Khi đó, biến thể kém bền nhiệt gây ra các triệu chứng lâm sàng và đặc điểm kết quả xét nghiệm tương tự như bệnh lí CPT II và đặc biệt, các xét nghiệm sàng lọc RLCHBS còn cho thấy acylcarnitine tăng trong máu đối với tất cả các dạng biến thể kể cả khi bệnh nhân bị nhiễm trùng hay không bị nhiễm trùng $[5],[6]$. Tuy nhiên, chưa có nghiên cứu kĩ lưỡng giữa ảnh hưởng của các dạng biến thể tới mức độ giảm hoạt độ của enzyme CPT II. Biến thể F352C và V368I tuy được phân loại ảnh hưởng lâm sàng lành tính/ có thể lành tính nhưng không thể bỏ qua nguy cơ có thể gây nên bệnh lí CPT II thứ phát, đặc biệt khi cơ thể bị nhiếm trùng.

\section{KẾT LUÂ̂N}

Bằng phương pháp giải trình tự gen xác định 16 biến thể trên gen SLC25A20 gây bênh CACT và 35 biến thể trên gen CPT2 gây bệnh CPT II giúp phân biệt chẩn đoán xác định bệnh lí RLCHBS di truyên CACT và CPT II, tạo điêu kiện cho việc chẩn đoán xác đinh, can thiệp điều trị và tư vấn di truyền đối với bệnh CACT và CPT II.

\section{TÀI LIÊU THAM KHẢO}

1. Chen, Y. M. (2005). Thermolabile phenotype of carnitine palmitoyltransferase II variations as a predisposing factor for influenza-associated encephalopathy. FEBS Letters, 579, 2040-2044.

2. Costa C, C. J. (2003). Mutational spectrum and DNA-based prenatal diagnosis in carnitineacylcarnitine translocase deficiency. Molecular Genetics and Metabolism, 78(1), 68-73

3. Fukushima, T. K. (2013). Three novel mutations in the carnitine-acylcarnitine translocase (CACT) gene in patients with CACT deficiency and in healthy individuals. Journal of Human Genetics, 58, 788-793.

4. Hsu BY, I. V. (2001). Aberrant mRNA splicing associated with coding region mutations in children with carnitine-acylcarnitine translocase deficiency. Molecular Genetics and Metabolism, 74, 248-255.

5. Lee RS, L. C. (2007). Carnitine-acylcarnitine translocase deficiency in three neonates presenting with rapid deterioration and cardiac arrest. Hong Kong Medical Jounal, 13, 66-68.

6. Mak, C. M. (2011). Fatal viral infection- 
associated encephalopathy in two Chinese boys: a genetically determined risk factor of thermolabile carnitine palmitoyltransferase II variants. Journal of Human Genetics, 56, 617-621.

7. Marsden, D. B. (2021). Impact of newborn screening on the reported incidence and clinical outcomes associated with medium- and long-chain fatty acid oxidation disorders. Genetics in Medicine, 23, 816-829.

8. Merritt, J. L. (2018). Fatty acid oxidation disorders. Annals of translational medicine, 24(6), 473.

\title{
KHÁNG THỂ KHÁNG BÀO TƯƠNG BACH CÂUU ĐA NHÂN TRUNG TÍNH TRONG BÊ̂NH LUPUS BAN ĐỎ HÊ THỐNG
}

\author{
Đỗ Thị Tùng Lâm*, Phạm Thị Vân Anh*, Nguyễn Văn Đoàn*
}

\section{TÓM TẮT}

Mục tiêu: Nghiên cứu nhằm khảo sát vai trò của các kháng thể kháng bào tương bạch cầu đa nhân trung tính trong bệnh lupus ban đỏ hệ thống Phương pháp nghiên cứu: Nghiên cứu mô tả cắt ngang trên 115 bệnh nhân được chẩn đoán lupus ban đỏ hể thống theo tiêu chuẩn SLICC 2012 điều tri tai Trung Tâm Dị Ứng Miễn Dịch Lâm Sàng Bệnh viện Bạch Mai từ tháng $7 / 2020$ đến tháng $9 / 2021$. Kết quả: Tỉ lệ ANCA , MPO - ANCA, PR3-ANCA dương tính lần lướt $33 \%, 3,5 \%, 32,2 \%$. PR3-ANCA dương tính liên qua tới nhóm bệnh nhân có thời gian mắc bệnh dưới 2 năm $(p=0,05)$. Biểu hiện lâm sàng thường gặp trong nhóm bệnh nhân SLE với ANCA, c-ANCA dương tính là là đaú khớp $(57,9 \%$ và $56,8 \%)$, ban cánh bướm $(26,3 \%$ và $24,3 \%)$, viêm phổi kẽ $(26,3 \%$ và $24,3 \%)$, tràn dịch đa màng $(34,2 \%$ và $35,1 \%)$ loét da, đâu chi $(18,4 \%$ và $18,9 \%)$, Raynaud $(16,2 \%$ và $16,7 \%)$ giảm C3 (97,4\% và $97,3 \%)$, giảm C4 $(84,2 \%$ và $83,8 \%$ ) và $100 \%$ bệnh nhân SLE có ANCA, C ANCA dương tính có dsDiNA dương tính. ANCA dương tính ở bênh nhân SLE liên quan tới các biểu hiện loét da, đâu chi $(O R=4,121, p=0,038)$, Raynaud ( $O R=$ $7,258, p=0,014)$, giảm $C 4(O R=4, p=0,004)$, tăng dsDNA (OR=1,561, $\mathrm{p}=0,029)$, mức độ hoạt động bênh nặng $(O R=2,829, p=0,017)$ Kết luận: Ở bệnh nhân lupus ban đỏ hệ thống, ANCA liên quan tới mức độ hoat động bênh nặng và tổn thương da, hiệ tượng Raynaud. Chưa thấy mối liên quan giữa ANCA với tổn thương thân trong SLE.

Tư khóa: SLE, lupus, c-ANCA, p-ANCA, SLEDAI, viêm thận lupus.

\section{SUMMARY}

ANTINEUTROPHIL CYTOPLASMIC ANTIBODIES IN SYSTEMIC LUPUS ERYTHEMATOSUS

Objectives: My research aims to examine the role of antineutrophil cytoplasmic antibodies in systemic lupus erythematosus. Methods and Methodology:

\footnotetext{
*Trường Đại học Y Hà Nội

Chịu trách nhiệm chính: Đỗ Thị Tùng Lâm

Email: drtunglam1005@gmail.com

Ngày nhận bài: 7.9.2021

Ngày phản biện khoa học: 28.10.2021

Ngày duyệt bài: 8.11.2021
}

This is cross-sectional descriptive study on 115 patients diagnosed with systemic lupus erythematosus according to SLICC 2012 Standard treated at the center of Allergology and Clinical Immunology in Bach Mai hospital from July 2020 to September 2021. Results: the percentage of antibodies ANCA, MPO ANCA, PR3-ANCA being positive are 33\%,3.5\%, $32.2 \%$, respectively. The positive antibody PR3-ANCA is relevant to the patients whose illness time is less than 2 years $(p=0.05)$. The common clinical characteristics in the SLE patients with positive ANCA, C-ANCA are arthritis $(57.9 \%$ and $56.8 \%)$, acute skin rash - butterflu rash $(26.3 \%$ and $24.3 \%)$, interstitial lung disease $(26.3 \%$ and $24.3 \%)$, multi membrane effusion $(34.2 \%$ and $35.1 \%)$, ulcers in skin $((18.4 \%$ và $18.9 \%)$, Raynaud (16.2\% và $16.7 \%)$, C3 deficiency $(97.4 \%$ and $97.3 \%)$, C4 deficiency (84.2\% and $83.8 \%$ ) and $100 \%$ of SLE patients who have positive ANCA, c - ANCA antibodies has positive dsDNA. The positive ANCA antibody in SLE patients relevant to characteristics such as ulcers in skin chi $(O R=4.121$, $p$ $=0.038)$, Raynaud $(\mathrm{OR}=7.258, \mathrm{p}=0.014)$, $\mathrm{C} 4$ deficiency $(\mathrm{OR}=4, \mathrm{p}=0.004)$, surplus dsDNA (OR= $1.561, \mathrm{p}=0.029)$, severe disease activity level (OR=2.829, $\quad \mathrm{p}=0.017)$. Conclusions: Patients diagnosed with systemic lupus erythematosus have ANCA antibody which is relevant to severe disease activity level and skin damage, Raynaud. There is no link or corelation between ANCA antibody with kidney damage in SLE.

Keywords: Systemic lupus erythematosus, ANCA, c-ANCA, SLEDAI, lupus nephritis

\section{I. ĐẶT VẤN ĐỀ}

Lupus ban đỏ hê thống [Ststemic lupus erythematosus $\{S L E\}]$ là bệnh lý tự miễn thường gặp đặc trưng bởi sự hình thành các tự kháng thể dẫn tới tổn thương đa cơ quan trong cơ thể ${ }^{1}$, tỷ lệ lưu hành trong khoảng 20-150 bệnh nhân/100.000 dân và tỷ lệ này cao hơn ở nữ khoảng 164 - 406 bệnh nhần/100.000 dân, tỷ lệ mắc bệnh đã tăng gần 3 lân so với 40 năm trước ${ }^{2}$. Đây là một bênh lý man tính xen kẽ giữa nhửng giai đoạn bệnh ổn định với các giai đoạn đợt cấp tiến triển gây nặng lên ở bất kỳ cơ quan nào với bệnh cảnh lâm sàng đa dạng và thay đổi ${ }^{3}$.

P-ANCA và C-ANCA là 2 kháng thể có thể gặp 